\title{
Motivation: We Need Psychobiosocial Model
}

\author{
Mohammad Qasim Abdullah* \\ Clinical Psychology, Faculty of Education, Syria
}

*Corresponding author: Mohammad Qasim Abdullah, Clinical Psychology, Faculty of Education, Syria

\section{Opinion}

Motivation has been studied in many ways over many years, historically, the concept of motivation derived from many different lines of inquiry. Morgane (1979) for example attacked the concept as mystical and without representation of nervous system. Now we can see that the concept represents the convergence of different lines of inquiry in the history of philosophy and sciences I will highlight on some viewpoints and global facts of new trends and theories of the concept. Why do we do what we do? Why do we feel what we feel? How can we change what we do and feel? What causes behavior? What starts, maintains, and stops behavior? Why does behavior vary in its intensity? Motivation is the process of initiating, sustaining, and directing psychological and physiological activities, including internal forces such as impulses, drives and desires involved in the process. Motives may operate on a conscious or unconscious level and are frequently divided into physiological (primary or organic, such as hunger and elimination), and psychological (secondary, or personal /social such as affiliation, competition and interests) [1]. Motivation and emotion derive from movere (Latin for "to move". Motivation refers to the processes that give behavior energy and direction Motivated behavior leads to rewards or reinforcement, which create in the promotion of new learning, and the maintenance of performance and achievement. On the other hand, the motivation can be measured preferences, interests, choices, aversions, and willingness to overcome barriers to achieve the goal, or to work and perform. At this point the approach/avoidance ply a significant role in understanding the dynamic basis of behavior, especially, the concept of conflicts.

Motivation conflicts is happened when two or more motives with each other resulting in frustration as in animal desiring food but waiting to avoid a flight with predator. Some motivational conflicts involve acquired motives. According to this view, I see that, social and environmental context ply an important role in the direction of motivated behavior. The motivation is inferred from behavior to account for the shifts in arousal and direction of behavior throughout the day and season. The motivated behavior may be aroused or derived by a change in the internal environment, by naturally arousing stimuli such as incentive, signs stimuli, and previously neutral stimuli that come to arouse because of learning and conditioning. The hypothalamus and other structures lining the ventricles received information from the internal environment through seven known cirecumventricular organs that lie outside the blood-brain barrier. The hypothalamus exerts over the internal environment through its influence on pituitary and through its connections with the brainstem such as dorsal vague complex. These connections allow it to participate in neural control over autonomic functions and metabolism. Learning and experience play significant roles in motivation and rewards (reinforcement). It is only with humans that we have a way of knowing about hedonic experience for we can measure pleasantness and unpleasantness with suitable rating scales or magnitude estimation techniques.

There is connection between motivation and creativity. The enjoyment is justification enough for intrinsic motivation, and the intrinsic motivation boosts creativity. On the other hand, personal relevance of a task causes intrinsic motivation [2]. Higher incentives do not always lead to better performance. Monetary incentives worsen performance in tasks that require creative problem solving. For complex tasks, people are driven by autonomy, mastery and purpose. Cultivate emotional ownership. As we suggested at the outset of this article, it is indeed an exciting time for the study of motivation-cognition -emotion interactions. Although studies of motivation have been an active focus within psychology and neuroscience for decades, there has clearly also been a recent rejuvenation of interest [3]. It is very important to investigate the relationship between motivation, emotion and cognition in personality. The field is now poised to make rapid progress on these and related questions, but that such progress will critically depend on the adoption of an integrative, collaborative approach. Psychological study of motivation searches for theories 
that describe the functions of motivation in natural systems such as humans and animals. New trend in investigating emotion is that the psychological theories of motivation are implementing in artificial systems [4].

\section{Conclusion}

we need an integrated/global model for investigating the motivation because it is complex phenomena. This model should be containing the psychobiosocial trend for approaching the goal of science: understanding, predicting and controlling the motivated behavior in personality [5]. Rudolf concluded, "Motivated behavior is complex. Obtaining goals - 'appetitive' behavior - involves the integration of cognitive knowledge about your goals with habits and the motivational impact of environmental stimuli (CSs). Once you've obtained your goal, you need to integrate complex 'consummatory' response patterns to use it. Structures within the brain's limbic system play an important role in appetitive and consummatory behaviors; we can distinguish those structures contributing to each".

\section{References}

1. Corsini R (2002) Dictionary of psychology. Brunner -Routledge. New York.

2. Abdullah MQ (2016) Introduction to mental health. Amman: Dar Al-fikr.

3. Braver TS, Krug MK, Chiew KS, Kool W, Westbrook JA, et al. (2014) mechanisms of motivation-cognition interaction; challenge and opportunities. Cogn Affect Behav neurosci 14(2): 443-472.

4. Kathryn M, Mary Lou (2014) Motivation theories for natural and artificial systems.

5. Rudolf N (2003) Emotion and motivation. NST 1B Psychology.

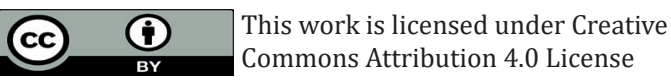

To Submit Your Article Click Here : Submit Article

DOI: $10.32474 /$ RRHOAJ.2019.03.000160

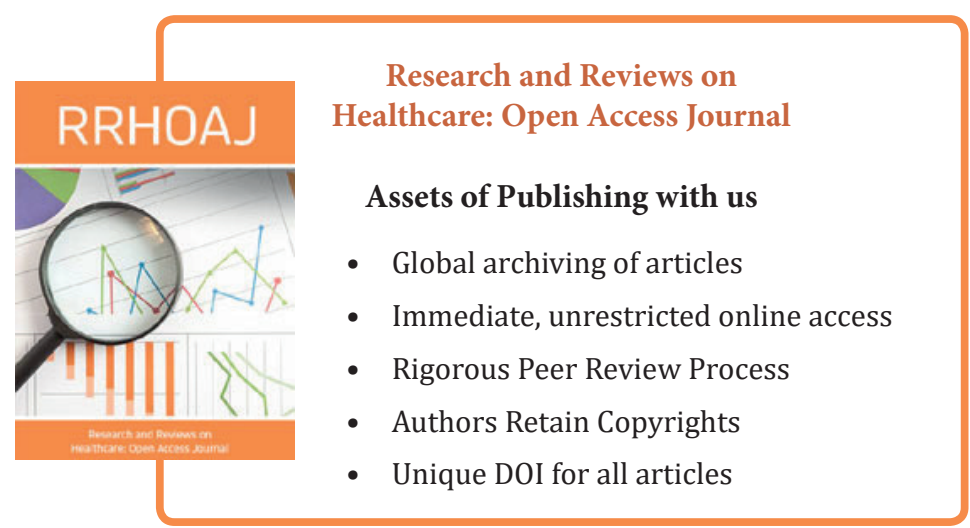

